\title{
Tissue Plasminogen Activator Toxicity after Submacular Hemorrhage Repair
}

\author{
Yasmin Islam MD; S. Gibran Khurshid MD \\ University of Florida College of Medicine, Department of Ophthalmology, Gainesville, Florida, USA \\ ORCID: \\ Yasmin Islam: https://orcid.org/0000-0001-8415-4215
}

J Ophthalmic Vis Res 2021; 16 (3): 507-510

\section{PRESENTATION}

A 76-year-old female presented with a history of non-exudative macular degeneration presented with a submacular hemorrhage $(\mathrm{SMH})$ due to conversion to exudative macular degeneration in the left eye [Figure 1]. Visual acuity had decreased to $20 / 200$. She underwent 23-gauge pars plana vitrectomy, subretinal injection of $0.2 \mathrm{~mL}$ of 25 $\mu \mathrm{g} / 0.1 \mathrm{~mL}$ tissue plasminogen activator (tPA) at $2 \mathrm{~mm}$ superotemporally to the hemorrhage, and $12 \% \quad C_{3} F_{8}$ gas fill. She postured supine with a $30^{\circ}$ forward head tilt for five days to facilitate displacement of the hemorrhage inferiorly. Two weeks after the operation, the hemorrhage had largely cleared, and her vision improved to 20/80, but she developed a crescent-shaped area of retinal pigment epithelium (RPE) atrophy extending beyond the area of tPA injection, with relative sparing of the posterior pole. Figure 2 demonstrates the fundus appearance at two weeks, and Figures 3-5 are the appearance at one month. While $\mathrm{SMH}$ can cause retinal toxicity from blood products, this patient's toxicity extended beyond the hemorrhage perimeter and corresponded to the area of

Correspondence to:

Yasmin Islam, M.D. Resident Physician, Department of Ophthalmology University of Florida, Gainesville, FL 1600 SW Archer Road, Gainesville, FL 32610, USA. E-mail: yislam3@gmail.com

Received: 30-01-2020 Accepted: 03-12-2020
tPA infiltration. This likely represents tPA-induced retinal toxicity.

\section{DISCUSSION}

Subretinal tPA to treat SMH is increasingly used due to its generally excellent outcomes. ${ }^{[1]}$ However, tPA can induce retinal toxicity in a dose dependent manner. Mild toxicity results in localized outer retinal dysfunction in rabbits, while severe toxicity can result in extensive retinal necrosis. ${ }^{[2]}$ Doses $\geq 50 \mu \mathrm{g}$ have definitively caused toxicity in rabbits and cats when injected intravitreally, ${ }^{[2,3]}$ while studies on toxic doses in humans are limited to case reports. Chen et al described the case of a 49-year-old male who developed tPA-induced RPE changes within five weeks after two $50 \mu \mathrm{g}$ injections of tPA for $\mathrm{SMH}$ into the vitreous cavity. Like our patient, the RPE degeneration extended past the area of $\mathrm{SMH}$, indicating likely tPA toxicity. ${ }^{[4]}$ Hesse et al similarly reported four patients who developed RPE hyperpigmentation after $100 \mu \mathrm{g}$ doses of intravitreal tPA. ${ }^{[5]}$ However, unlike these prior cases, our patient developed toxicity with a single $50 \mu \mathrm{g}$ tPA dose subretinally. It is unclear if lower dosages will be safe in the subretinal space, and further studies need to be performed evaluating the safest dosages for subretinal tPA injection.

This is an open access journal, and articles are distributed under the terms of the Creative Commons Attribution-NonCommercial-ShareAlike 4.0 License, which allows others to remix, tweak, and build upon the work non-commercially, as long as appropriate credit is given and the new creations are licensed under the identical terms.

How to cite this article: Islam Y, Khurshid SG. Tissue Plasminogen Activator Toxicity after Submacular Hemorrhage Repair. J Ophthalmic Vis Res 2021;16:507-510. 


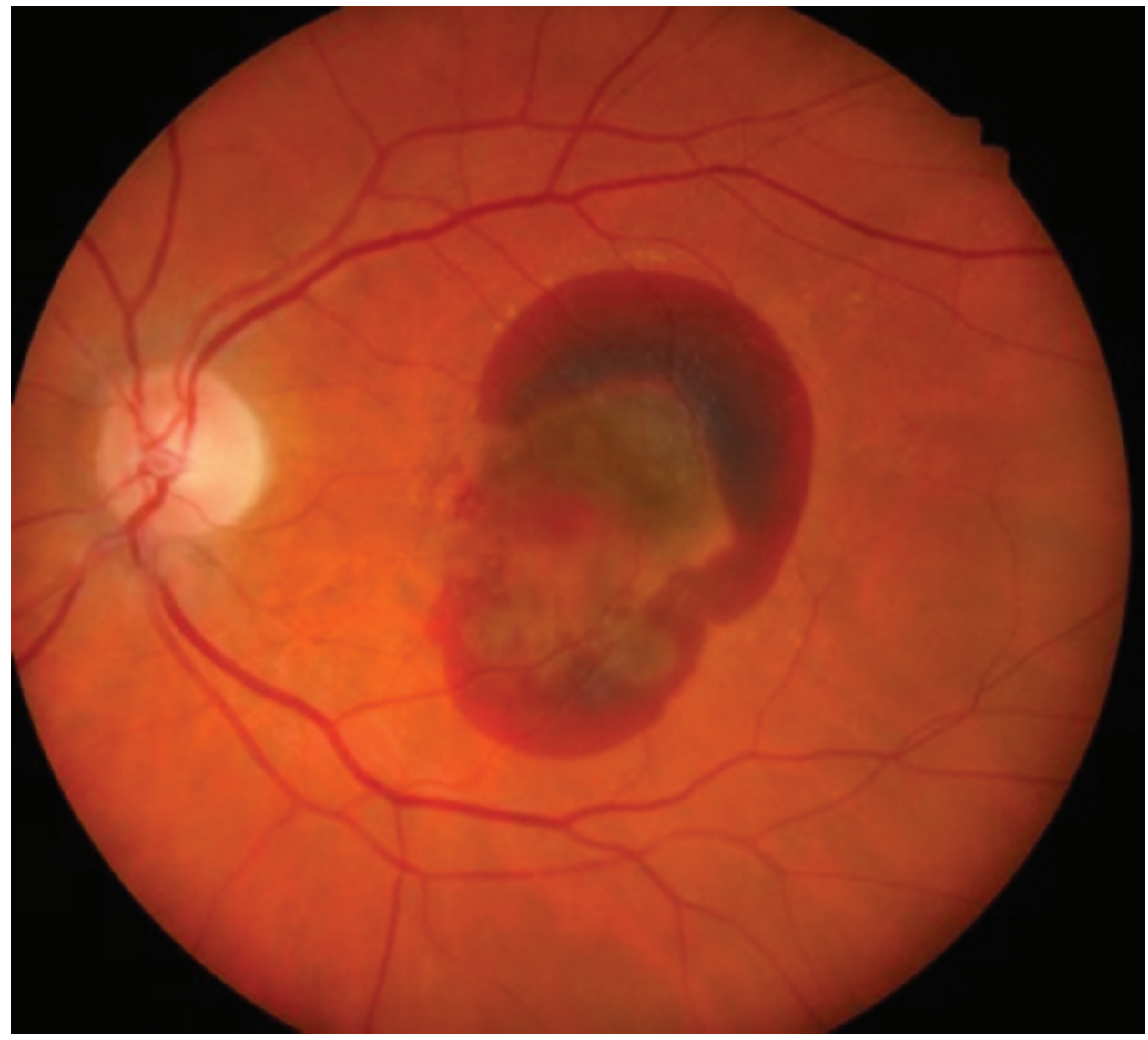

Figure 1. Preoperative color fundus photo demonstrating a large submacular hemorrhage.

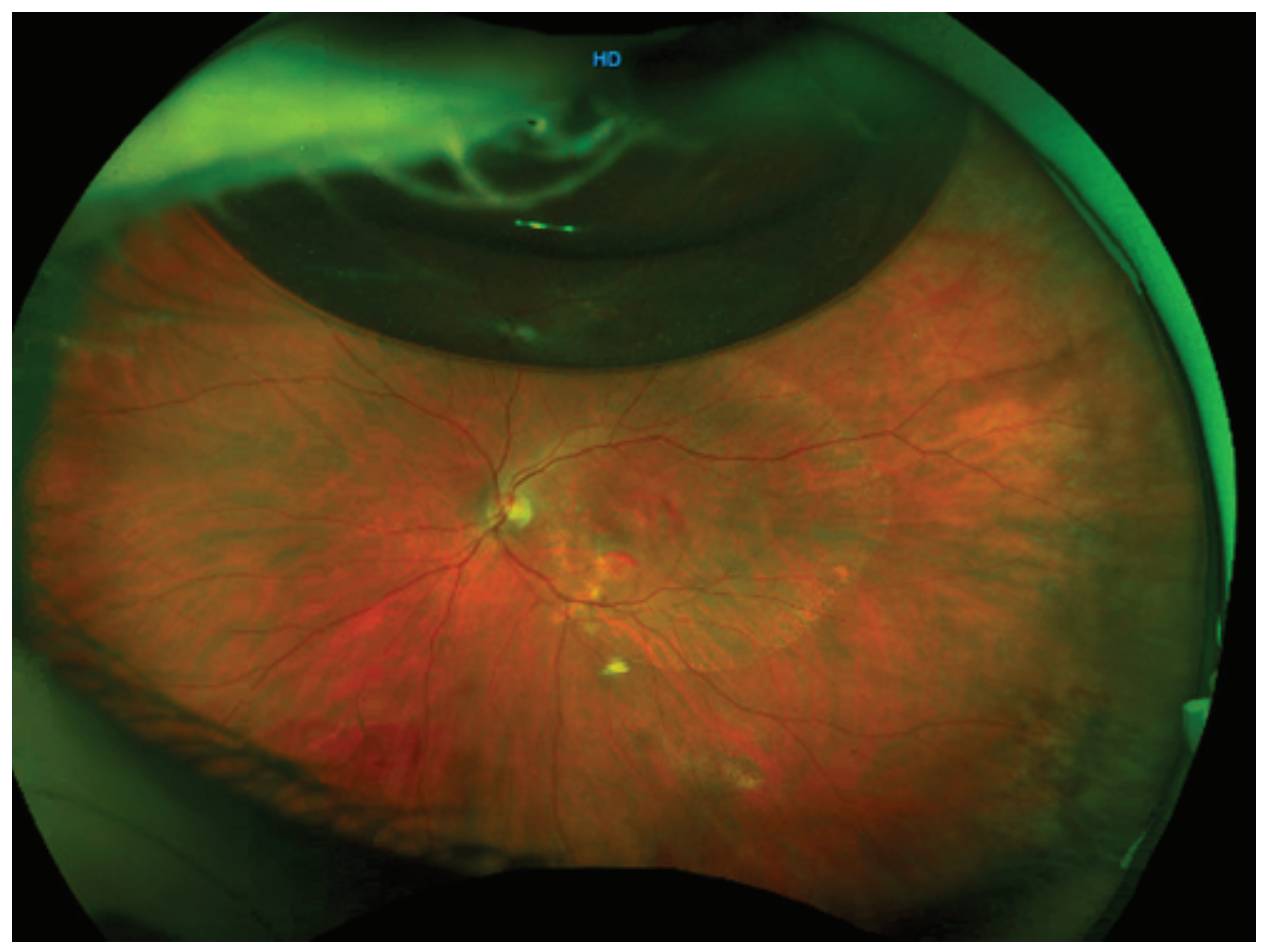

Figure 2. Color fundus photo taken at postoperative week two, demonstrating resolving submacular hemorrhage but new retinal pigment epithelium atrophy extending beyond the area of prior hemorrhage. $\mathrm{A}_{3} \mathrm{~F}_{8}$ gas bubble is also present superiorly. 


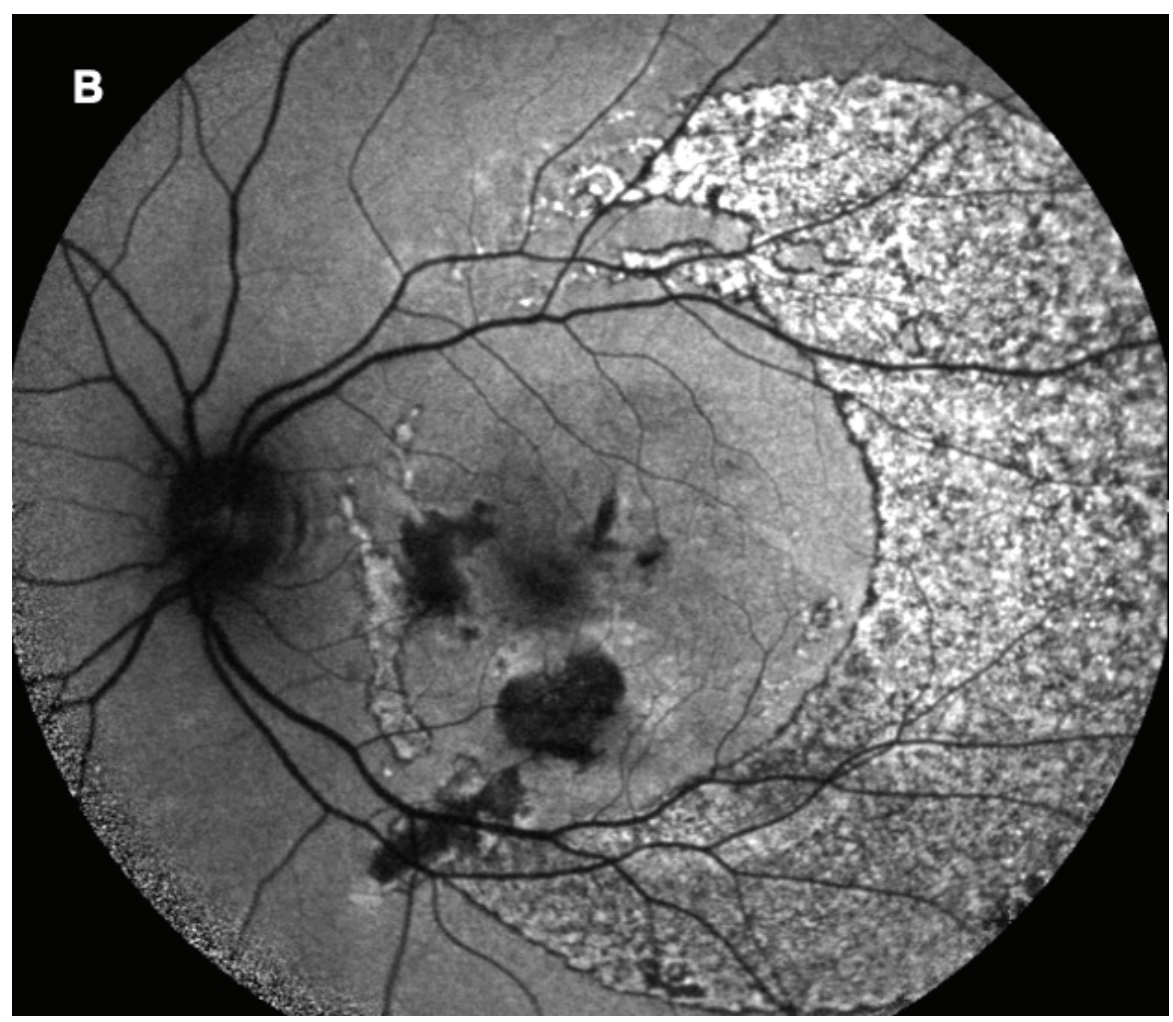

Figure 3. Fundus autofluorescence demonstrating the area of damaged retinal pigment epithelium over the macula that extends temporally at one month postoperatively. There is diffuse hyper-autofluorescence temporal to the macula with areas of hypoautofluorescence, demonstrating likely retinal pigment epithelium atrophy with areas of hyperplasia.

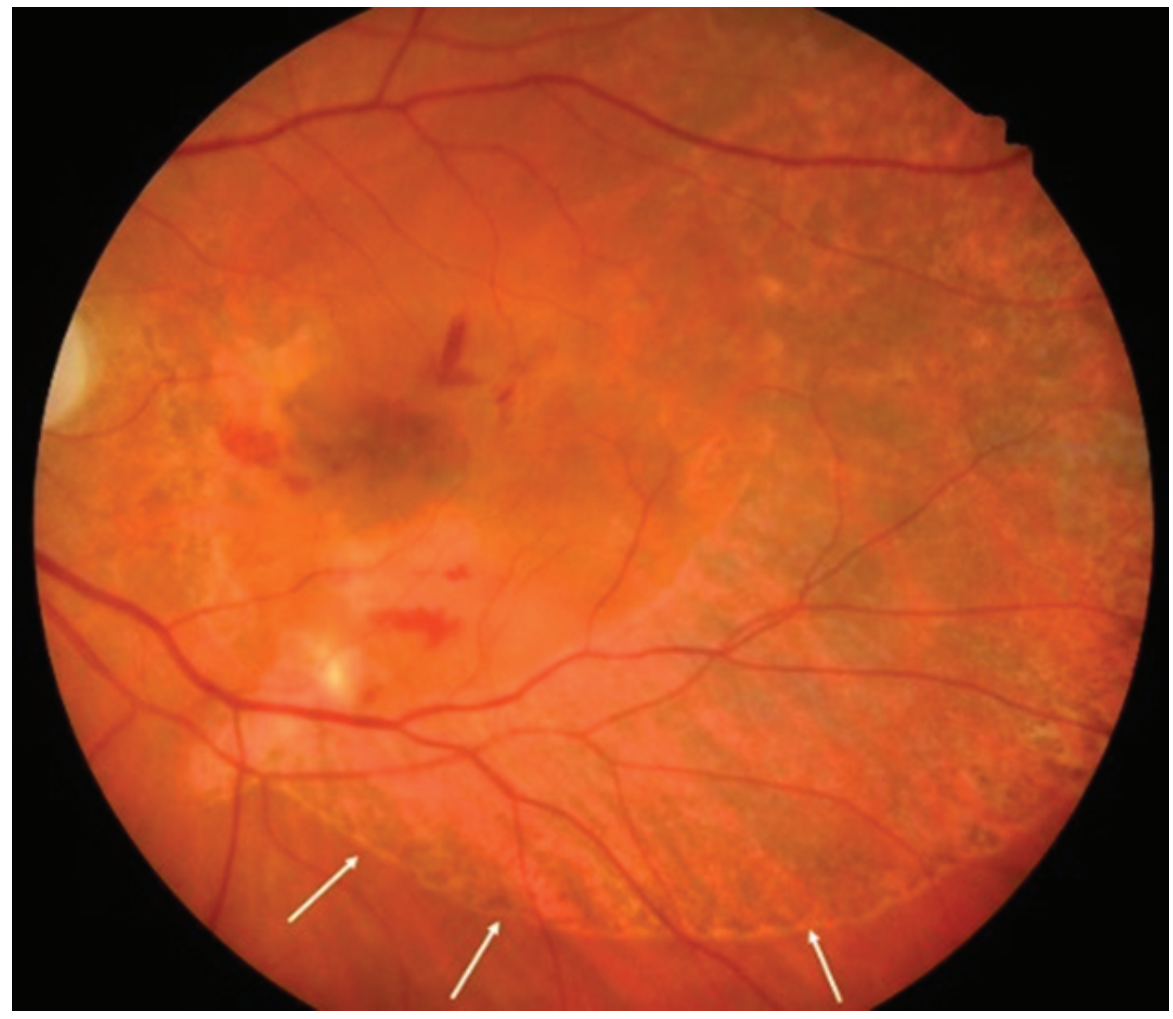

Figure 4. Color fundus photo demonstrating resolved submacular hemorrhage and RPE damage extending from the optic disc to the arcades and the temporal edge of the macula at one month postoperatively. Arrows demonstrate the extent of retinal pigment epithelium damage. 


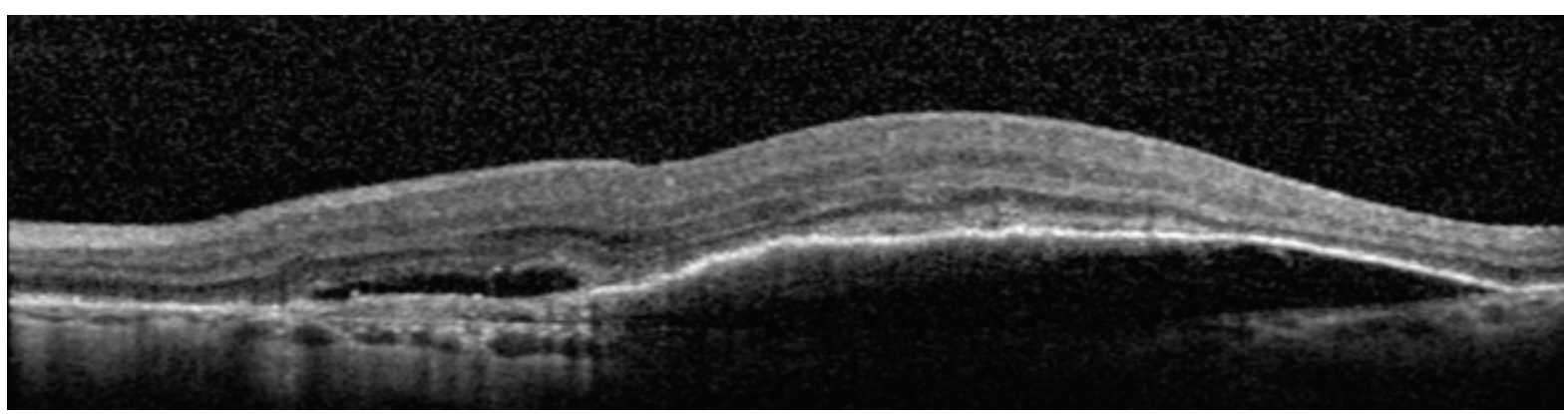

Figure 5. Macular optical coherence tomography at the first postoperative month demonstrating a resolving submacular hemorrhage and retinal pigment epithelium atrophy.

\section{Declaration of Patient Consent}

The authors certify that they have obtained all appropriate patient consent forms. In the form the patient has given her consent for her images and other clinical information to be reported in the journal. The patient understand that her name and initial will not be published and due efforts will be made to conceal his identity, but anonymity cannot be guaranteed.

\section{Financial Support and Sponsorship}

Nil.

\section{Conflicts of Interest}

There are no conflicts of interest.

\section{REFERENCES}

1. Juncal VR, Hanout M, Altomare F, Chow DR, Giavedoni LR, Muni RH, et al. Surgical management of submacular hemorrhage: experience at an academic Canadian centre. Can J Ophthalmol 2018;53:408-414.

2. Johnson MW, Olsen KR, Hernandez E, Irvine WD, Johnson RN. Retinal toxicity of recombinant tissue plasminogen activator in the rabbit. Arch Ophthalmol 1990;108:259263.

3. Hrach CJ, Johnson MW, Hassan AS, Lei B, Sieving PA, Elner VM. Retinal toxicity of commercial intravitreal tissue plasminogen activator solution in cat eyes. Arch Ophthalmol 2000;118:659-663.

4. Chen SN, Yang TC, Ho CL, Kuo YH, Yip Y, Chao AN. Retinal toxicity of intravitreal tissue plasminogen activator: case report and literature review. Ophthalmology 2003;110:704-708.

5. Hesse L, Schmidt J, Kroll P. Management of acute submacular hemorrhage using recombinant tissue plasminogen activator and gas. Graefes Arch Clin Exp Ophthalmol 1999;237:273-277. 